\title{
Evaluation Of The Relationship Between Neutrophil-Lymphocyte Ratio and Insulin Resistance In Newly Diagnosed Type 2 Diabetes Mellitus Patients Mohamed Nabil Rafat ${ }^{1}$, Mahmoud Saad Berengy ${ }^{2}$, Hesham Samir Abd alsamie ${ }^{3}$, Sallam El-sayed Ramadan ${ }^{* 2}$ \\ ${ }^{1}$ Department of Internal Medicine; Faculty of Medicine, Al-Azhar University (Cairo) \\ ${ }^{2}$ Department of Internal Medicine; ${ }^{3}$ Department of Clinical Pathology; Damietta Faculty of Medicine, Al- Azhar University \\ *Corresponding author: Sallam El-sayed Ramadan, Mobile: (+20) 01019674370, E-Mail: sallam.elsayed15@yahoo.com
}

\begin{abstract}
Background: Newly diagnosed type 2 diabetes mellitus (DM) is associated with insulin resistance (IR). This insulin resistance is related to state of chronic inflammation and inflammatory marker such as neutrophil lymphocyte ratio, which can be used as a predictor inflammatory marker for insulin resistance.

Objectives: The aim of this study was to evaluate the relationship between neutrophil-lymphocyte ratio and insulin resistance in newly diagnosed type 2 diabetes mellitus in New Demitta Hospital patients.

Patients and methods: This study is a prospective one that was carried out on thirty (30) populations and sixty (60) patients newly diagnosed type 2 diabetes mellitus attending to Outpatient Clinic and Inpatient Department of Internal Medicine at Al-Azhar University Hospital, Damietta. All were subjected to full history and clinical examination, laboratory tests include, HOMA IR, HbA1c, serum fasting insulin, CBC, Fasting blood sugar, post prandial glucose level, ALT, AST, serum albumin, bilirubin, GGT, creatinine, urea, uric acid, cholesterol, triglycerides, HDL cholesterol, LDL cholesterol, high sensitive C-reactive proteins, ESR, BMI and urine analysis.

Results: Our study showed that there was statistically significant increased neutrophil-lymphocyte ratio and serum triglycerides in group newly diagnosed type 2 diabetes mellitus with IR (BI) in comparison with newly diagnosed type 2 diabetes mellitus without IR group (BII) and controlled group (A).The study showed a significant positive correlation of NLR with HOMA-IR and showed the risk predictors of IR including NLR, TG and HbA1c.
\end{abstract}

Conclusion: The results of this study showed that in newly diagnosed type 2 DM with IR having increased NLR which can be considered as early predictor for IR in those patients.

Keywords: Neutrophil-lymphocyte ratio (NLR), Insulin resistance (IR), Inflammation, Type 2 Diabetes mellitus.

\section{INTRODUCTION}

Diabetes mellitus is a metabolic disorder characterized by hyperglycemia that develops as a consequence of defects in insulin secretion, insulin action, or both. Type 2 diabetes encompasses individuals who have insulin resistance (IR) and usually relative (rather than absolute) insulin deficiency ${ }^{(1)}$. Shaw et al. ${ }^{(2)}$ reported that by the year 2030, Egypt will have at least 8.6 million adults suffering the disease.

The exact molecular action leading to IR is not yet understood, but several studies have confirmed the relationship between systemic inflammation and insulin resistance, in which an altered immune system plays a decisive role in the pathogenesis of $\mathrm{DM}^{(3)}$. Patients with T2 DM are in a state of lowdegree chronic inflammation that induces hypersecretion of inflammatory factors, such as CRP, IL-6, TNF- $\alpha$ and MCP-1, which results in a constantly elevated neutrophil granulocyte count ${ }^{(4)}$.

Neutrophil to lymphocyte ratio (NLR) rather than other white cell parameters (e.g., total white cell, monocyte count and absolute neutrophil count) was found to be a useful inflammatory marker that predicts adverse outcomes in many medical and surgical conditions ${ }^{(5)}$. Celikbilek et al. ${ }^{(6)}$ observed that NLR possesses a diagnostic value in certain pathologies characterized by systemic or local inflammatory response such as diabetes mellitus. Moreover, lymphocytes may be also associated with inflammation. Some studies showed that IR may be related to the signal transduction mediated by $T$ cells and that IR results in a decrease in T-cell count ${ }^{(7)}$.

Elevated neutrophil/lymphocyte ratio (NLR) was associated with a higher prevalence of diabetes. This association concurs with existing literature that describes these conditions as proinflammatory ${ }^{(8)}$.

One mechanism by which increased levels of neutrophils could mediate IR may be through augmented inflammation. The increase in NLR appears to underlie the elevated levels of proinflammation, as evident from the persistent neutrophil activation and enhanced release of neutrophil proteases with $\mathrm{T} 2 \mathrm{DM}^{(9)}$. 


\section{AIM OF THE WORK}

The aim of this study was to evaluate the relationship between neutrophil-lymphocyte ratio and insulin resistance in newly diagnosed type 2 diabetes mellitus in New Damietta Hospital patients.

\section{SUBJECTS AND METHODS}

This is a cross-sectional study comparing relationship between neutrophil-lymphocyte ratio and insulin resistance in newly diagnosed type 2 diabetes mellitus patients. The study included 60 (sixty) newly diagnosed $\mathrm{T} 2 \mathrm{DM}$ attending to Internal Medicine Outpatient Clinic and 30 (thirty) apparently healthy volunteers as a control group divided as follow:

Group A: 30 (thirty) apparently healthy volunteers matched for age and sex as a control. Group B: 60 (sixty) newly diagnosed type 2 DM patients attending to Internal Medicine Outpatient Clinic.

\section{-Diagnostic criteria by the American Diabetes Association (ADA) included the following:}

1- A fasting plasma glucose (FPG) level of 126 $\mathrm{mg} / \mathrm{dL}(7.0 \mathrm{mmol} / \mathrm{L})$ or higher, or 2- A 2-hour plasma glucose level of $200 \mathrm{mg} / \mathrm{dL}(11.1 \mathrm{mmol} / \mathrm{L})$ or higher during a $75-\mathrm{g}$ oral glucose tolerance test (OGTT), or 3- A random plasma glucose of 200 $\mathrm{mg} / \mathrm{dL}(11.1 \mathrm{mmol} / \mathrm{L})$ or higher in a patient with classic symptoms of hyperglycemia or hyperglycemic crisis. 4- A hemoglobin A1c (HbA1c) level of $6.5 \%$ or higher.

\section{Exclusion criteria:}

- Patients with type $1 \mathrm{DM}$.

- Patients with infections, for example, urinary tract infection (UTI), upper respiratory tract infection, lower respiratory tract infections, gastrointestinal infection, and pyrexia of unknown origin.

- Patients with systemic disorder such as cardio vascular disease (CVD), chronic liver disease, chronic kidney disease (CKD), any microvascular complication, autoimmune and blood disorders.

- Patients on anti-inflammatory drugs, systemic or topical steroids, angiotensin converting enzyme inhibitors, angiotensin II receptor blockers, alcohol and patients with uncontrolled blood pressure (BP).

\section{Methods}

A. Full history taking and thorough clinical examination.B. Duration of DM. C. Treatment history. D. age and sex. E. Smoking and alcohol intake history. F. Family history. G. Other chronic illness was collected( History of hypertension and its relation to DM, - History of neuropathy, retinopathy and other complications. - History of angina, myocardial infarction, heart failure or cerebral stroke. - History of hypoglycemic attacks or repeated hospital admission. - History of drug intake).

Laboratory investigation: CBC. Serum Fasting Insulin. Serum Fasting Glucose. Two hour postprandial glucose. HbAlc, liver function test (ALT, AST, PT, INR, albumin and bilirubin). Kidney function test (serum creatinine, BUN, serum uric acid and urine analysis). ESR, CRP, lipid profile, HOMA IR and BMI.

\section{Ethical approval: \\ The study was approved by the Ethics Board of Al-Azhar University.}

\section{Statistical methods}

Data were collected, coded, revised and enter ed to the Statistical Package for Social Science (IBMSPSS) version 20. The data were presented a $\mathrm{s}$ number and percentages for the qualitative data, mean, standard deviations and ranges for the quantitative data with parametri $\mathrm{c}$ distribution and median with inter quartile range (IQR) for the quantitative data with nonparametric distribution. Chi

square test was used in the comparison between $t$ wo groups with qualitative data and Fisher exact test was used inst ead of the Chi square test when the expected count in any cell found less than 5 .

The comparison between more than two grou ps with quantitative data and parametric distributi on were done by using One Way Analysis of Variance e (ANOVA) test and KruskallWallis test was used in the comparison between more than two groups with quantitative data and $n$ on-parametric distribution.

\section{RESULTS}

divided into:

Group B 60 patient (type 2 DM) sub-

Group BI (43 patients type 2 DM with insulin resistance) and Group BII (17 patients type 2 DM without insulin resistance). 
Table (1): Statistical comparison between group BI (DM with IR), group BII ( DM without IR) \& control group $\mathrm{A}$ as regards $\mathrm{HBA} 1_{\mathrm{C}}$ and $\mathrm{CBC}$

\begin{tabular}{|l|l|l|l|l|l|l|l|l|}
\hline \multicolumn{2}{|l}{} & \multicolumn{2}{l}{$\begin{array}{l}\text { Controlled group A } \\
\text { (No.=30) }\end{array}$} & \multicolumn{2}{l|}{$\begin{array}{l}\text { Group BII (DM } \\
\text { without IR) } \\
\text { (No.=17) }\end{array}$} & \multicolumn{2}{l|}{$\begin{array}{l}\text { Group BI (DM } \\
\text { with IR) } \\
\text { (No.=43) }\end{array}$} & \multicolumn{2}{l|}{$\begin{array}{l}\text { One way } \\
\text { ANPVA }\end{array}$} \\
\cline { 2 - 10 } & Mean & SD & Mean & SD & Mean & SD & f & $\begin{array}{l}\text { P } \\
\text { value }\end{array}$ \\
\hline HBA1 & 5.35 & 0.69 & 8.38 & 1.07 & 10.68 & 1.36 & $\begin{array}{l}198.57 \\
8\end{array}$ & 0.001 \\
\hline WBCs & 5.86 & 0.78 & 5.29 & 1.27 & 5.29 & 0.80 & 4.022 & 0.067 \\
\hline HGB & 11.70 & 2.34 & 11.64 & 1.66 & 11.48 & 1.34 & 0.142 & 0.868 \\
\hline PLT & 261.17 & 8.21 & 257.12 & 8.73 & 265.12 & 3.23 & 0.096 & 0.908 \\
\hline $\begin{array}{l}\text { Neutroph } \\
\text { il }\end{array}$ & 3.57 & 0.04 & 3.50 & 0.90 & 4.61 & 1.47 & 8.217 & 0.089 \\
\hline $\begin{array}{l}\text { Lymphoc } \\
\text { yte }\end{array}$ & 1.59 & 0.28 & 1.27 & 0.26 & 1.16 & 0.25 & 135.17 & 0.165 \\
\hline Post hoc test & $\begin{array}{l}\text { Controlled VS DM } \\
\text { without IR }\end{array}$ \\
\hline
\end{tabular}

There was statistically significant increase in $\mathrm{HBA} 1_{\mathrm{C}}$ in group BI (DM with IR) in comparison with group BII (DM without IR) and control group A.

Table (2): Statistical comparison between group BI (DM with IR), group BII (DM without IR) \& control group A as regards lipid profile

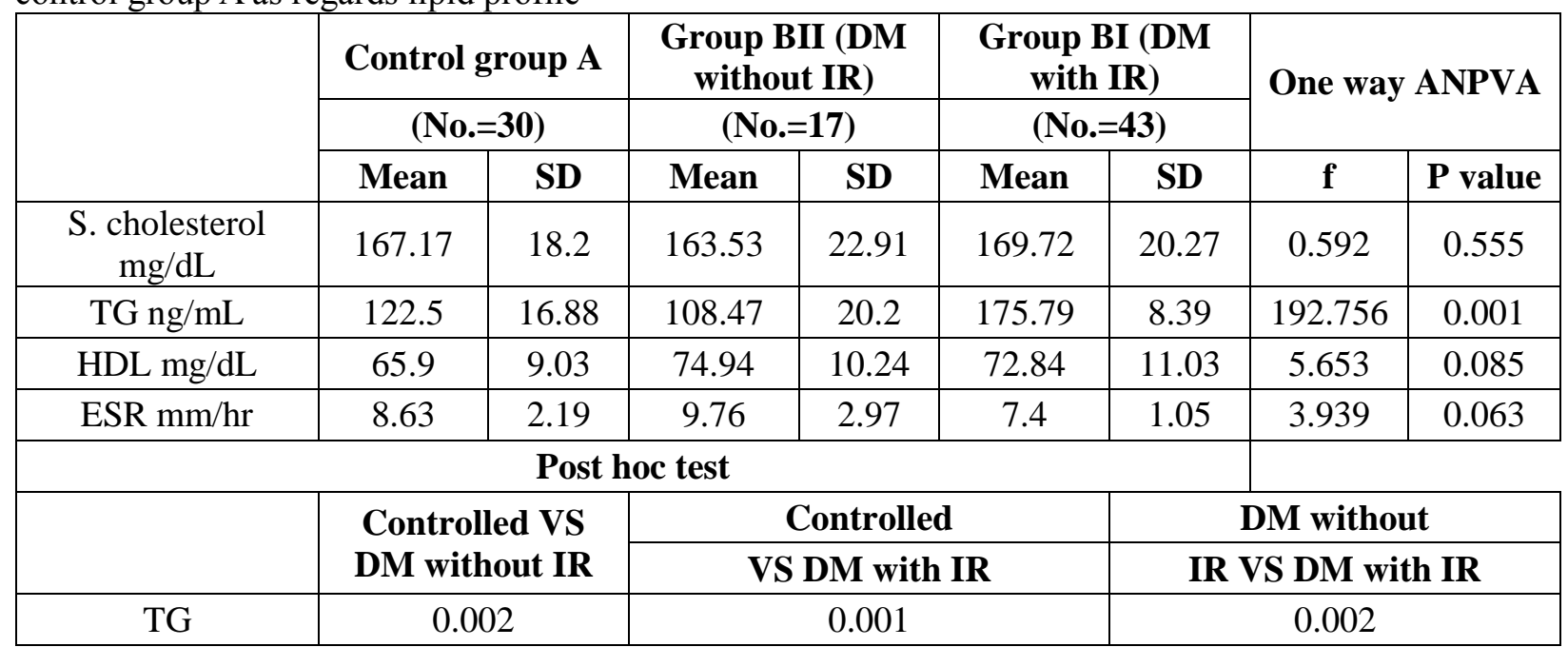

Normal lipid profile in all groups as regards serum cholesterol, HDL and LDL. There was significant increase in TG level in DM with IR in comparison with DM without IR and control group.

Table (3): Statistical comparison between group BI (DM with IR), group BII (DM without IR) \& control group A as regards CRP

\begin{tabular}{|l|l|l|l|l|l|l|l|l|l|}
\hline \multicolumn{2}{|l|}{} & \multicolumn{2}{|l|}{$\begin{array}{l}\text { Controlled group } \\
\text { A (No.=30) }\end{array}$} & $\begin{array}{l}\text { Group BII (DM } \\
\text { without IR) } \\
\text { (No.=17) }\end{array}$ & $\begin{array}{l}\text { Group BI (DM } \\
\text { with IR) } \\
\text { (No.=43) }\end{array}$ & \multicolumn{2}{l|}{ Chi square test } \\
\hline & No & $\%$ & No & \% & No & \% & X $^{\mathbf{2}}$ & P value \\
\hline CRP & Negative & 28 & $93.4 \%$ & 14 & $82.3 \%$ & 5 & $11.6 \%$ & 61.869 & 0.001 \\
\hline & Positive & 2 & $6.7 \%$ & 3 & $17.6 \%$ & 39 & $90.7 \%$ & & \\
\hline
\end{tabular}

There was statistically significant difference in CRP regarding studied group. As regards the diabetic patient, CRP was positive in 39 patients with IR, while negative in 5 patients. Also, it was positive in 3 patients without IR, while negative in 14 patients. CRP was more strongly positive in diabetic patients with IR than in diabetic patients without IR and control group. 
Table (4): Statistical comparison between group BI (DM with IR), group BII (DM without IR) \& control group A as regards IR and NLR

\begin{tabular}{|c|c|c|c|c|c|c|c|c|}
\hline & \multicolumn{2}{|c|}{$\begin{array}{l}\text { Controlled } \\
\text { group A } \\
(\text { No. }=\mathbf{3 0})\end{array}$} & \multicolumn{2}{|c|}{$\begin{array}{l}\text { Group BII (DM } \\
\text { without IR) } \\
(\text { No.=17) } \\
\end{array}$} & \multicolumn{2}{|c|}{$\begin{array}{l}\text { Group BI (DM with } \\
\text { IR) } \\
(\text { No.=43) }\end{array}$} & \multicolumn{2}{|c|}{$\begin{array}{l}\text { One way } \\
\text { ANPVA }\end{array}$} \\
\hline & Mean & SD & Mean & SD & Mean & SD & f & $\begin{array}{l}\mathbf{P} \\
\text { value }\end{array}$ \\
\hline FBS mg/dL & 87.40 & 9.85 & 162.82 & 28.61 & 188.37 & 28.36 & $\begin{array}{l}23.65 \\
8\end{array}$ & 0.164 \\
\hline PPBS mg/dL & $\begin{array}{l}124.5 \\
0\end{array}$ & 6.85 & 289.18 & 52.45 & 276.84 & 45.89 & $\begin{array}{l}26.35 \\
0\end{array}$ & 0.095 \\
\hline $\begin{array}{l}\text { S.INSULIN } \\
\mathrm{mcU} / \mathrm{mL}\end{array}$ & 7.72 & 1.68 & 6.24 & 0.80 & 11.78 & 2.93 & $\begin{array}{l}15.65 \\
8 \\
\end{array}$ & 0.125 \\
\hline HOMA IR & 1.63 & 0.29 & 1.71 & 0.20 & 5.39 & 1.26 & $\begin{array}{l}195.2 \\
75\end{array}$ & 0.001 \\
\hline NLR & 1.40 & 0.35 & 2.79 & 0.87 & 4.29 & 0.95 & $\begin{array}{l}121.1 \\
00\end{array}$ & 0.001 \\
\hline \multicolumn{9}{|l|}{ Post hoc test } \\
\hline & \multicolumn{2}{|c|}{$\begin{array}{l}\text { Controlled VS } \\
\text { DM without IR }\end{array}$} & \multicolumn{3}{|c|}{\begin{tabular}{|l} 
Controlled \\
VS DM with IR \\
\end{tabular}} & \multicolumn{3}{|c|}{$\begin{array}{l}\text { DM without IR } \\
\text { VS DM with IR }\end{array}$} \\
\hline HOMA IR & \multicolumn{2}{|c|}{0.774} & \multicolumn{3}{|c|}{0.001} & \multicolumn{3}{|l|}{0.001} \\
\hline NLR & \multicolumn{2}{|l|}{0.001} & \multicolumn{3}{|l|}{\begin{tabular}{|l|}
0.001 \\
\end{tabular}} & \multicolumn{3}{|l|}{0.001} \\
\hline
\end{tabular}

There was statistically significant increase in DM with IR in comparison with DM without IR and control group with HOMA IR and NLR. HOMA IR was high in 43 type 2 DM patients (group BI) associated with increased NLR in 39 patients type 2 DM and normal NLR in 4 patients type 2 DM (group BI). While, HOMA IR was normal in 17 patients type 2 DM (group BII) associated with normal NLR in 14 patients type $2 \mathrm{DM}$ and increased NLR in 3 patients type $2 \mathrm{DM}$ (group BII).

Table (5): Demographic and laboratory data of the patient and control groups

\begin{tabular}{|l|l|l|l|}
\hline Variable & $\begin{array}{l}\text { Diabetes patients } \\
\text { without } \\
\text { IR( BI)( } \mathbf{n = 1 7 )}\end{array}$ & $\begin{array}{l}\text { Diabetes patients } \\
\text { (BII) with IR }(\mathbf{n}=\mathbf{4 3})\end{array}$ & $\begin{array}{l}\text { Healthy subjects (A) } \\
(\mathbf{n}=\mathbf{3 0})\end{array}$ \\
\hline Age(year) & $58.82 \pm 5.76$ & $58.58 \pm 5.49$ & $55.33 \pm 7.25$ \\
\hline $\begin{array}{l}\text { Sex: male } \\
\text { female }\end{array}$ & $\begin{array}{l}6(35.29 \%) \\
11(64.70 \%)\end{array}$ & $\begin{array}{l}22(51.16 \%) \\
21(48.83 \%)\end{array}$ & $\begin{array}{l}13(43.33 \%) \\
17(56.66 \%)\end{array}$ \\
\hline BMI & $25.47 \pm 2.96$ & $24.72 \pm 2.07$ & $24.48 \pm 1.70$ \\
\hline Creatinin mg/dL & $1.06 \pm 0.17$ & $1.02 \pm 0.16$ & $1.06 \pm 0.28$ \\
\hline TG ug/L & $108.47 \pm 20.20$ & $175.79 \pm 8.39$ & $122.50 \pm 16.88$ \\
\hline T.Cholesterol mg/dL & $163.53 \pm 22.91$ & $169.72 \pm 20.27$ & $167.17 \pm 18.20$ \\
\hline HDL mg/dL & $74.94 \pm 10.24$ & $72.84 \pm 11.03$ & $65.90 \pm 9.03$ \\
\hline FBG mg/dL & $162.82 \pm 28.61$ & $188.37 \pm 28.36$ & $87.4 \pm 9.85$ \\
\hline PPBG & $289.18 \pm 52.45$ & $276.84 \pm 45.89$ & $124.50 \pm 6.85$ \\
\hline HBA1c & $8.38 \pm 1.07$ & $10.6 \pm 1.36$ & $5.35 \pm 0.69$ \\
\hline HOMA IR & $1.71 \pm 0.20$ & $5.39 \pm 1.26$ & $1.63 \pm 0.29$ \\
\hline NLR & $2.79 \pm 0.87$ & $4.29 \pm 0.95$ & $1.40 \pm 0.35$ \\
\hline WBCs & $5.29 \pm 1.27$ & $5.29 \pm 0.80$ & $5.86 \pm 0.78$ \\
\hline Neutrophil & $3.50 \pm 0.90$ & $4.61 \pm 1.47$ & $3.57 \pm 1.04$ \\
\hline Lymphocyte & $1.27 \pm 0.46$ & $1.16 \pm 0.25$ & $1.59 \pm 0.48$ \\
\hline Microalbuminura & NIL & NIL & NIL \\
\hline & & & \\
\hline
\end{tabular}




\section{DISCUSSION}

IN our study, we found that there was no statistically significant difference between DM with IR, DM without IR and control group as regards age in years and anthropometric measure (BMI) and sex. This is in agreement with the result of the study of Sefil et al. ${ }^{(10)}$ who reported that there was a positive correlation between NLR and $\mathrm{HbA1c}$ but not with BMI. In contrast with the result of the study of Wellen and Hotamisligil (11) who found that BMI for general obesity is risk factor for HOMA-IR in T2DM.

In our study, the result showed that the degree of IR increased significantly with the rising level of HbAlc. In agreement with our result, Heianza et al. ${ }^{(12)}$ reported that elevated $\mathrm{HbAlc}$ levels of above $41 \mathrm{mmol} / \mathrm{mol}(>5.9 \%)$ were associated with a substantial reduction in insulin secretion and insulin sensitivity as well as an association with $\beta$-cell dysfunction with subsequent increase IR. On the other hand, Kim et al. ${ }^{(13)}$ reported that HbA1c showed an association with early-phase insulin secretion assessed by insulinogenic index. As with increasing serum insulin there is increase in HBA1c and vise visra.

In this study, the result showed that there was statistically significant increase in TG level in DM with IR in comparison with DM without IR and control group while normal lipid profile in all group in regard to serum cholesterol, HDL and LDL. In contrast with the results of our study, Jayanthi ${ }^{(14)}$ reported that increased accumulation of TG has been observed in human muscle tissue of obese and type 2 diabetic subjects, and was associated with IR. In addition, BlachnioZabielska (15) observed that IR reduced the inhibitory effect of lipolysis in adipose tissue, resulting in the increase of free fatty acids (FFA) level in plasma. Infusion of free fatty acids (FFA) has been shown to induce IR in skeletal muscles.

In our study, we found that there was statistically significant difference in CRP regarding studied groups.

There was more +ve CRP in diabetic group with IR (90.7\% of total DM with IR) than diabetic without IR and control group, which explains that IR is related to a state of chronic inflammation. IN agreement with our study, Bilgir et al. (16) observed that there was positive correlation between HOMA-IR and CRP concentration and that the severity of inflammatory response was reported in several studies. Besides, Lou et al. ${ }^{(17)}$ showed that patients with T2DM are in a state of low-degree chronic inflammation that induces hypersecretion of inflammatory factors, such as CRP, IL-6, TNF- $\alpha$, and MCP-1, which results in a constantly elevated neutrophilic granulocyte count.

The result of our study showed that there was statistically significant increase in DM with IR in comparison to DM without IR and control group concerning HOMA IR and NLR. HOMA IR was high in $43(71 \%$ of total $60 \mathrm{DM})$ type $2 \mathrm{DM}$ patients associated with 1-Increased NLR in 39 (91\%) patient type 2 DM. 2- Normal NLR in 4 (9\%) patients type 2 DM (group BI). HOMA IR was normal in $17(28 \%$ of total $60 \mathrm{DM})$ patients type $2 \mathrm{DM}$ associated with normal NLR in 14 (82\%) patients type 2 DM and Increased NLR in 3 (17\%) patient type $2 \mathrm{DM}$ (group BII).

A meta-analysis, the data synthesized from 20 observational studies, showed a positive association between total WBC and the risk of developing type 2 diabetes mellitus.

This analysis also showed that higher levels of granulocytes and lymphocytes, but not monocytes, were asso

ciated with incidence of type 2 diabetes (18). Subjects with increased concentrations of both $\mathrm{CRP}$ and $\mathrm{WBC}$ had the most unfavorable metabolic profile compared to those having low CRP and/or low WBC, including HOMA-IR. The combination of high CRP and high WBC was associated with the highest risks of IR and T2DM ${ }^{(\mathbf{1 8})}$. Imtiaz et al. (19) observed that Insulin resistance and pancreatic b-cell dysfunction are the two most critical pathophysiological abnormalities underlying type 2 diabetes. While previous studies have consistently reported a positive association between total WBC and insulin resistance ${ }^{(19)}$.

NLR was found to be a significant risk factor for IR with DM through logistic regression analysis. The pathological activation of innate immunity leads to inflammation of the islet cells, resulting in a decrease in pancreatic beta-cell mass and impaired insulin secretion ${ }^{(20)}$.

NLR serves an important function in predicting the risk of IR. IR in diabetic patients is related to chronic inflammation, and NLR may be helpful in assessing the prognoses of these patients (17). Imtiaz et al. (19) said that, NLR is more sensitive and simple clinical indicator of IR compared to the neutrophilic granulocyte count and CRP levels, which are widely used as markers of IR.

\section{CONCLUSION}

The result of this study showed that newly diagnosed type 2DM with IR had increased NLR, which can be considered as early predictor for IR in those patients. 


\section{REFERENCES}

1. Inzucchi SE, Bergenstal RM, Buse JB et al. (2012): Management of Hyperglycemia in Type 2 Diabetes: A Patient-Centered Approach Position Statement of the American Diabetes Association (ADA): and the European Association for the Study of Diabetes (EASD): Diabetes Care, 35 (6): 13641379.

2. Shaw JE, Sicree RA, Zimmet PZ (2010): Global estimates of the prevalence of diabetes fo and 2030. Diabetes Res Clin Pract., 87 (1): 4-14.

3. Shoelson S, Lee J, Goldfine A (2006): Inflammation and insulin resistance. J Clin Invest., 116: $1793-1801$.

4. Tabák AG, Kivimäki M, Brunner EJ et al. (2010): Changes in C-reactive protein levels before type 2 diabetes and cardiovascular death: the Whitehall II study. Eur J Endocrinol., 163: 89-95.

5. Zahorec $R$ (2001): Ratio of neutrophil to lymphocyte counts-rapid and simple parameter of systemic inflammation and stress in critically ill. Bratisl Lek Listy., 102 (1): 5-14.

6. Celikbilek M, Dogan S, Ozbakır O et al. (2013): Neutrophil-lymphocyte ratio as a predictor of disease severity in ulcerative colitis. J Clin Lab Anal., 27: 72-76.

7. Lorenzo C, Hanley AJ, Haffner SM (2014): Differential white cell count and incident type 2 diabetes: the insulin resistance atherosclerosis study. Diabetologia, 57: 83-92.

8. Azab B, Zaher M, Weiserbs KF et al. (2010): Usefulness of neutrophil tolymphocyte ratio in predicting short- and long-term mortality after nonST-elevation MI. Am J Cardiol., 106 (4): 470476

9. Buyukkaya E, Karakas MF, Karakas E et al. (2014): Correlation of neutrophil to lymphocyte ratio with the presence and severity of metabolic syndrome. Clin Appl Thromb Hemost., 20 (2): 15963.

10. Sefil F, Ulutas KT, Dokuyucu $R$ et al. (2014): Investigation of neutrophil lymphocyte ratio and blood glucose regulation in patients with type 2 diabetes mellitus. J Int Med Res., 42 (2): 5818-22.
11. Wellen KE, Hotamisligil GS (2005): Inflammation, stress and diabetes. J Clin Invest., 115: 1111-1119.

12. Heianza Y, Arase Y, Fujihara K et al. (2012): High normal $\mathrm{HbA}(1 \mathrm{c})$ : levels were associated with impaired insulin secretion without escalating insulin resistance in Japanese individuals: the toranomon hospital health management center study 8 (TOPICS 8): Diabet Med., 29: 1285-1290.

13. Kim TN, Park MS, Lee SK et al. (2012): Elevated A1C is associated with impaired early-phase insulin secretion rather than insulin resistance in Koreans at high risk for developing diabetes. Endocrine, 42: 584-591.

14. Jayanthi R, Srinivasan AR, Hanifah M et al. (2017): Associations among Insulin resistance, triacylglycerol/high density lipoprotein (TAG/HDL ratio): and thyroid hormone levels - a study on type 2 diabetes mellitus in obese and overweight subjects. Diabetes \& Metabolic Syndrome: Clinical Research \& Reviews, 11: 121-126.

15. Blachnio-Zabielska AU, Chacinska $M$, Vendelbo MH et al. (2016): The crucial role of C18-Cer in fat-induced skeletal muscle insulin resistance. Cellular Physiology and Biochemistry, 40 (5): 1207-1220.

16. Bilgir O, Yavuz M, Bilgir F et al. (2018): Relationship between insulin resistance, hs-CRP, and body fat and serum osteoprotegerin/RANKL in prediabetic patients. Minerva Endocrinol., 43: 1926.

17. Lou M, Luo P, Tang R et al. (2015): Relationship between neutrophil-lymphocyte ratio and insulin resistance in newly diagnosed type 2 diabetes mellitus patients. BMC Endocr Disord., 15: 9-13.

18. Gkrania-Klotsas E, Ye Z, Cooper AJ et al. (2010): Differential white blood cell count and type 2 diabetes: systematic review and metaanalysis of cross-sectional and prospective studies. PLoS One, 5: $13405-8$.

19. Imtiaz F, Shafique K, Mirza SSA et al. (2012): Neutrophil lymphocyte ratio as a measure of systemic inflammation in prevalent chronic diseases in Asian population. Int Arch Med., 5: 2-6.

20. Gorasia DG, Dudek NL, Veith PD et al. (2014): Pancreatic beta cells are highly susceptible to oxidative and ER stresses during the development of diabetes. J Proteome Res., 14 (2): 688-99. 